\title{
MANAGEMENT ACTIVITIES EFFECTIVENESS IN MODERN RUSSIAN INSTITUTION IN THE CONTEXT OF HEAD WORKPLACE MODELING
}

Elmira K. Semenova $^{1 *}$, Yuriy G. Volkov ${ }^{2}$, Vladimir V. Uzunov ${ }^{3}$, Alexander V. Popov ${ }^{4}$, Anna V. Vereshchagina ${ }^{5}$ ${ }^{1}$ North Caucasus State Academy, Russia and Pyatigorsk State University, Department of Creative Innovation Management and Law, Pyatigorsk, Russia, ${ }^{2,4,5}$ Southern Federal University, Institute of Sociology and Regional Studies, Rostov-on-don, Russia, ${ }^{3}$ Russian Academy of Sciences, Crimean Branch of the Federal Research Sociological Center, Simferopol, Russia. Email: ${ }^{1 *}$ elmirasemen@icloud.com, ${ }^{2}$ ugvolkov@ @fedu.ru, ${ }^{3}$ vladimir.uzunov@mail.ru, ${ }^{4}$ avpopov11@ gmail.com, 5 anrietta25@mail.ru

\section{Article History: Received on $30^{\text {th }}$ August 2019, Revised on $28^{\text {th }}$ September 2019, Published on $22^{\text {nd }}$ October 2019}

\section{Abstract}

Purpose: The scientific approach to the organization of labor and the workplace of the institution head involves the search for the most optimal model or technique acceptable to the Russian conditions within the current management culture, traditional views on the nature of managerial work, the scale and effectiveness of management activities.

Methodology: Methodological guidelines for the study of workplaces' organization of credit and financial institutions' heads are based on the provisions of modern ergonomics and the principles of a system-based approach, allowing justifying as a significant one the environment-oriented approach.

Result: The obtained results served as the basis for the development of appropriate recommendations to optimize the current situation in the context of eliminating existing gaps and problems in the credit and financial sector of the Russian economy from the standpoint of optimizing the process of organizing working places for managers of institutions in this profile.

Applications: This research can be used for universities, teachers, and students.

Novelty/Originality: In this research, the model of the Management Activities Effectiveness in Modern Russian Institution in the context of Head Workplace Modeling is presented in a comprehensive and complete manner.

Keywords: management activity, the efficiency of management activity, credit and financial institutions, the head, the workplace of the head.

\section{INTRODUCTION}

Almost everywhere, as experts say, Russian production is inefficient and uncompetitive (Bovykin, 2013), which can be explained by the logic of the crisis development of society's socio-economic sphere, determining the importance of addressing the problem of management activities' efficiency in Russian organizations, including credit and financial profile. The latter is built into the system of modern market relations, which are not easy for Russia in the light of the geopolitical situation and crisis factors in the functioning of the economic sphere, and, in many ways, determine the financial climate in Russian society, and therefore need the closest attention from the scientific community.

This fact determines the importance of sociological research of this problem, in the present work, which is being implemented in the perspective of studying the organization of heads' workplaces of credit and financial organizations. This strategy is based on taking into account as a determining factor the impact of non-economic factors on the institution's effectiveness and management. It is difficult not to agree with the fact that in modern socio-economic realities the activity of credit and financial institutions' heads, as well as any other business-type institution, is associated with the influence of many risk factors that form a stressful management background and cause increased attention to the conditions of management of the head, to his workplace, which should be organized in such a way as to ensure the most effective level of work in the field of management decision-making and regulation of organizational processes. The development of the latter takes place in the conditions of high dynamics of changes in the external environment, exposed to the impact of globalization processes, crisis factors of the Russian economy and market competition, which many Russian financial institutions cannot stand, which is associated with a steadily low level of trust in them from the population, as well as a request for the search for an optimal model of effective organization and effective management. And in this model, as the researchers believe, we should not focus only on the specifics of the Russian mentality and national character, but should actively take into account best practices in business and management (Korgova and Pogosyan, 2015; Kutuev et al., 2016).

Thus, the problem of workplace organization of Russian credit and financial institutions' heads needs a deep sociological reflexing as socially significant in terms of financial and economic instability and the crisis of the Russian reality, as well as differing by scientific relevance associated with the lack of conceptual developments in this direction in management sociology.

\section{LITERATURE REVIEW}

The layer of scientific research presented on the topic of the article allows us to state that in the sociological literature, not all its aspects have become the subject of deep reflexing, and in particular, we are talking about the problem of the head workplace's organization in the context of the effectiveness of his/her management activities. Particularly to the 
development of sociological problems associated with the specificity of credit and financial institutions' functioning, the peculiarities of administrative activity of the administrative Board in the context of the banking sector's functioning in the modern Russian reality dedicated their scientific research I.A. Azhieva and M.A. Korgova (2018), M.G. Magomedov, N.M. Solovyova and A.V. Arutyunyan (2015), Eisvandi et al, (2015), etc.

Features of credit-financial institutions' functioning in Russian society as an integral part of the banking system are discussed in the works of such scientists as A.V. Gribovsky and R.A. Lizakov (2013), M.A. Korgova (2015), J.A. Nakhabina (2016). The researchers analyze the problems of credit and financial institutions' functioning from the point of view of the history of the banking system in Russia and the modern realities of credit and financial services' provision to the population in conditions of low income, imperfections of the state policy of regulation of the banking sector, high dependence on foreign capital, in accordance with which they offer ways and directions of optimizing the work of credit and financial institutions from the standpoint, first of optimizing public policy in relation to this sector of the economy.

It is impossible not to note a significant contribution of representatives of the foreign management scientific school to the development of the topic related to the workplace's organization of the modern institution's head, (Dul and Bruder, 2012; Hovanec et al., 2012, Kleiner, 2008; Hendrick, 1991; Mintzberg, 1973; Milgram and Kishino, 2014; Ameen et al, 2018; Haghshenas et al, 2015), as well as the importance of those studies that focus on the influence of ethnocultural factors in the formation of management culture and activities, as well as the creative factor as an indicator of managerial efficiency (Courtney, 2018).

Nevertheless, despite this range of research, now there are a number of issues related to the sociological study of the organization of the modern leader's workplace as a factor in the effectiveness of his professional activities in modern Russian institutions of the credit and financial sphere that remain scientifically unenlightened and conceptually unformed. This fact determines the scientific and cognitive situation in the field of research of this problem as requiring independent sociological study.

\section{RESEARCH METHODOLOGY}

Methodological guidelines for the study of workplaces' organization of credit and financial institutions' heads are based on the provisions of modern ergonomics and the principles of a system-based approach, allowing justifying an environmentoriented approach as a significant one. From its methodological position under the head's workplace in this study is proposed to understand the workspace, functionally organized for the implementation by the head of his/her management functions and solutions of production tasks aimed at achieving the goals of the institution. The methodological strategy of the research is based on the following guidelines: 1) universal factors determined by economic risks, the growth of market competition, dependence on the global trends of socio-economic development, etc. are more applicable to the specifics of the credit and financial sphere., 2) in relation to the organization of the space for the implementation of management functions as a significant factor in the design of the heads' workplace of credit and financial institutions, socio-cultural and civilizational aspects become important, which determine the different styles of organization of the head's workplace in world management. The main criterion for the effectiveness of management activities, from the point of view of effective organizations of the modern commercial world, is the degree of implementation of the institution's goals in relation to the interests of its employees.

To examine the state of leaders' workplaces in the Russian credit-financial institutions ten banking offices were selected, geographically located in the town of Pyatigorsk: Binbank (PSC), Vozrozhdenie (PSC), Bank VTB 24 (PSC), Gazprombank (SC), Eurocitybank (PSC), MDM Bank (PSC), Moscow Industrial Bank (PSC), Raiffeisen Bank (SC), and Russian Agricultural Bank (SC) Sberbank of Russia (PSC).

According to the results of the study, the authors developed the concept to improve the organization of heads' workplaces of Russian credit and financial institutions, including the phased implementation of three activities: 1) identification of the specifics and detail of job descriptions and working conditions of the head on the basis of the proposed passport of the heads' workplaces of the banking institution; 2) simulation of the head's workplace taking into account the proposed authors' combined model of the working multifunctional space; 3) certification of specific managers' workplaces in order to optimize and modernize them in a timely manner.

\section{RESULTS}

Credit and financial institutions are divided into two types: 1) credit and financial institutions as banks that carry out all banking operations within the existing legislation in the state; 2) non-Bank credit and financial institutions that carry out certain types of banking operations, as a rule, from among those that are not engaged in banking organizations. The second type of credit and financial institutions in the scientific literature is also called specialized credit and financial institutions (organizations), focused mainly on lending to certain, usually narrow sectors of the economy, so that they have a specific clientele and compete with each other (Kravtsova et al, 2014).

The number of specialized non-Bank credit and financial institutions, which include investment, insurance, financial, pension and other institutions, in modern Russia is very small, although all over the world there is rapid growth due to a decrease in the share of banking institutions. Among the reasons for this situation in Russia, researchers call low incomes, 
low rates of the securities market's development, and hence the underdevelopment of the sphere of special services that are designed to provide these institutions (Gribovsky and Lizakov, 2013). Thus, the basis of the Russian credit system is banking organizations, despite the poor quality of banking assets because of the crisis in the country's economy.

According to the results of the empirical study conducted by the authors, the Bank structures that occupy leading positions both in terms of overall performance and ergonomics were identified from among the analyzed ones; outsider banks, as well as banking institutions that occupy the so-called intermediate position, striving for an ideal balance between the overall efficiency of activity and its ergonomic component, but in practice which are not implementing the full cycle of workplace organization, in particular its appropriate assessment, reorganization and renewal.

Schematically, the results of the analysis can be presented as follows (Figure 1)

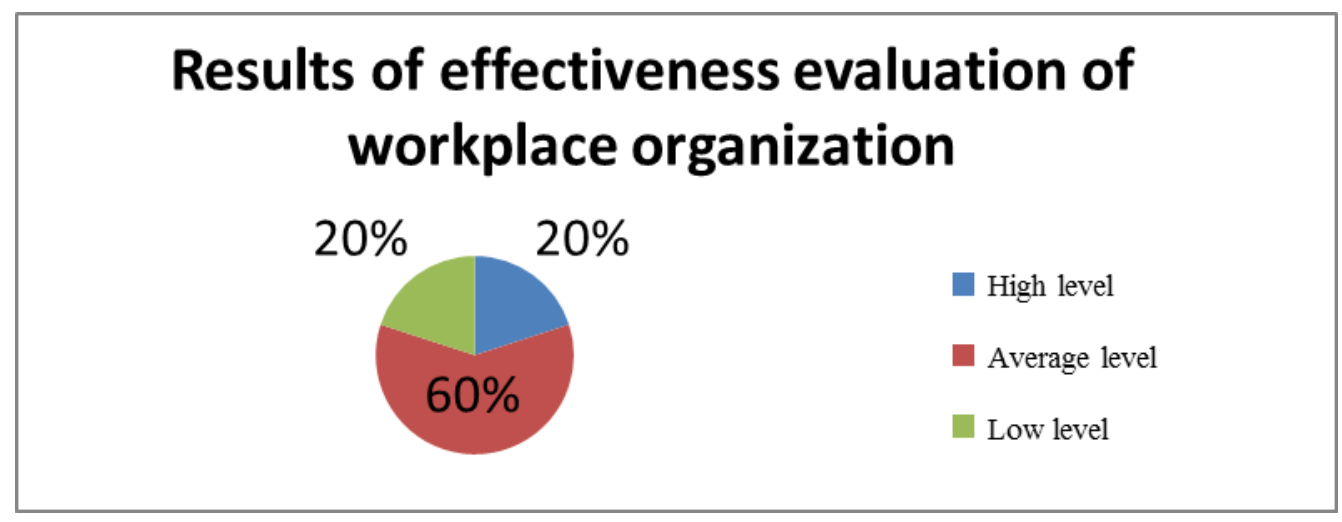

Figure 1: Results of effectiveness evaluation of workplace organization

We attributed Sberbank of Russia and VTB Bank 24 to the leading banks demonstrating a high level of efficiency and a strict approach to the ergonomics of the heads' working space; Gazprombank, Eurocitybank, MDM Bank, Moscow Industrial Bank, Raiffeisenbank, Rosselkhozbank were attributed to the group of banks that occupy an intermediate position and demonstrate a satisfactory level of efficiency with positive growth dynamics; Binbank and Vozrozhdenie were attributed to the group of banks with low performance and inappropriate approach to the scientific organization of labor in general and the organization of the head's workplace.

The obtained results served as the basis for the development of appropriate recommendations to optimize the current situation in the context of eliminating existing gaps and problems in the credit and financial sector of the Russian economy from the standpoint of optimizing the process of organizing workplaces for managers of institutions of this profile. The proposed recommendations are based on the key provision on the need to transform approaches to the organization of the head's workplace in accordance with the requirements of modern ergonomics, considering the workplace from not only the General standpoint of the workspace's formation, but also from the standpoint reflecting its status and professional and personal characteristics.

In this regard, we propose as a mandatory procedure to introduce the development of a workplace passport (PWP), reflecting the key parameters of the head's professional activity and his working conditions.

At a minimum, the PWP should include the following sections:

1. The purpose of the working space (characteristics of the institution/unit; the specificity of the organizational structure; staffing/personnel structure).

2. Brief description of the duties of the Manager (including requirements to the level of qualification, knowledge, and skills)

3. Analysis of working conditions (characteristics of the premises, the total area of the office, the microclimate of the premises, the compliance of the premises with the expected duties/methods and techniques of work).

4. The download of workplace/labor regulation (the regulatory complexity in totality; the actual total regulatory complexity; work schedule (days of the week, the presence of a break, etc.).

5. Furniture, equipment and technical mean (availability/ their lack; compliance with the duties performed; the degree of involvement in the working processes; technical parameters and characteristics; quantity).

6. Organization of the workplace maintenance process (Services responsible for the repair and technical updating of equipment, maintenance of the cleanliness of the working room, services that audit the condition of the working room, furniture, and equipment in order to update and conduct timely repairs (with contact phone numbers).

7. Occupational health and safety at the workplace (norms and parameters that ensure safety at the workplace; equipping the workplace with appropriate equipment and guidance documents). 
8. More information about the workplace.

It is possible to adjust the passport of the workplace and increase its level of adaptability to real working conditions by taking into account the opinion of managers themselves regarding the specifics of their professional activities. Systematization of managers' views in this regard will be contributed by the study of their opinions and positions based on a special questionnaire containing the following aspects:

1. Personal data of the Manager.

2. Description of the main elements of the Manager's work and the approximate time spent on solving typical tasks.

3. Comments on the scope and complexity of the functions performed.

4. Determination of variability level of working activities and the causes of the situation.

5. Description rush work situations (downs/ups; tides in the documentation, the complexity of reporting, an increase in the number of personal contacts, zones of tranquility/silence).

6. The presence of overtime (amount and reason).

7. Assessment of the possibility of increasing the volume of work without overtime (additional functional responsibilities, functional expansion).

8. Proposals to improve the workplace and optimize the working environment.

9. Degree of mobility in the workplace (static/dynamic position).

In accordance with the obtained data, the stage of modeling the workplace of the Manager should be carried out, which will allow designing it both with the focus on solving common organizational problems and with the focus on a specific user and his/her professional tasks.

Thus, the presented step-by-step approach to the organization of the head working space of the credit and financial sector, as well as any other business, will increase the level of management activities' efficiency of the head and the institution as a whole.

\section{DISCUSSION}

In the context of a rather complex socio-economic situation in the country, which is characterized by unstable employment indicators, such as high turnover in the Russian economy, accompanied by periods of long-term unemployment, largely covering rural youth and people of pre-retirement age, the activities of credit and financial institutions are also significantly complicated, since its effectiveness is largely due to the economic well-being of the population.

The basis of our concept consists of three main postulates, which in its phased implementation will qualitatively organize the workplace of the head:

- A modern ergonomic approach to the organization of WP should be based on the industry specifics of the institution as a whole and the specific features of the activities of a Corporation's specialist. In this regard, the first stage of the conceptual approach to the organization of WP should be to identify this specificity and detail job descriptions and working conditions of a particular specialist (in our case - the head);

- Ergonomics as an independent branch of knowledge innovates under the influence of environmental conditions, in particular under the influence of scientific and technological progress and socio-economic working conditions. Therefore, modeling of the Manager's workplace should be carried out at the second stage, taking into account not only the requirements of the scientific organization of labor but also industry principles and current trends in the development of ergonomic knowledge;

- Changing working conditions, changing socio-economic realities, increasing the dynamics of production life necessitate a systematic assessment of specific workplaces. In this regard, the workplace of the staff in general and of the Manager in particular needs periodic certification in order to be optimized and modernized in a timely manner.

The initial data for the development of workplace's passport can be standard passports of WP, models of workplaces of employees, the working draft of the building and the scheme of technical means' installation, standards of areas (according to scientific organization of labor), as well as internal documents of the following order: the staffing of the enterprise, the regulation on remuneration and divisions, job descriptions and employment contracts. Such an approach to the development of PWP will contribute to taking into account not only the technical but also the organizational and managerial components of labor (in our case - the head of the organization).

The second stage, related to the workplace modeling, in particular for the Manager, should be based on the results of the previous stage, that is, according to the workplace passport, and be built in accordance with the requirements and achievements of modern ergonomics on the basis of the following design principles: 
- The principle of the maximum orientation of the workplace to a particular user, its capabilities, skills, as well as anthropological characteristics (height, weight, etc.);

- The principle of problem orientation of the workplace to the solution of the corresponding organizational problems;

- The principle of the workplace's compliance with the information needs of the user, that is, the compliance of the workplace's equipment to the tasks that the user must perform, which will eventually save the office and the desktop from unnecessary items/technical devices or, conversely, will equip them.

Thus, the information provided must be clearly taken into account in the development of the design project of the head's office, otherwise the owner of the office will experience systematic discomfort both in terms of color design of the room and in terms of its furniture, which as a result can lead either to destabilization of the working regime, psychological discomfort, or to endless alterations of the workplace for themselves.

The third phase should be devoted to the evaluation/certification of the workplace in order to optimize it or for complete restructuring. At the same time, evaluation procedures should be carried out in at least two directions: certification of WP from the position of SOL (including sanitary and hygienic standards) and from the position of the employee (convenience of the workplace, the optimality of its organization for performing specific professional tasks, etc.).

The process of certification of the Workplace should begin primarily with its classification, for which we propose to use the following authors' table. (See Table 1)

Table 1: Classification of workplaces

\begin{tabular}{ll}
\hline Classification feature & Types of workplace \\
\hline by the degree of mechanization & manual, machine-manual, mechanized, automated, hardware, combined \\
\hline on the basis of specialization & specialized, universal \\
\hline on the basis of labor division & individual, collective \\
\hline on the basis of stability & stationary, mobile \\
\hline
\end{tabular}

When assessing the layout of workplaces, we propose to introduce the following certification criteria:

- Optimal use of working space for the organization of the corresponding WP;

- The optimal size of the office space;

- The effectiveness/correctness of the placement of equipment/ technical tools/ objects of labor within availability reach;

- Free access to the workplace;

- Optimal viewing area;

- Ensuring optimal storage conditions for working materials (including their availability);

- The comfort of the microclimate within the Workplace (including sanitary and hygienic standards and requirements);

- Comfort/ergonomics of furniture within WP;

- The orderliness of work materials in the first place on the desktop;

- The ratio of ergonomic and anthropometric indicators;

- Quality and level of technical equipment;

- Design of the workspace.

Certification of workplaces will be most effective if managers themselves are necessarily involved in this process.

At the next stage, the ratio of indicators of external criteria assessment and internal assessment of the workplace by the employee should be carried out, as a result of which the relevant conclusions, recommendations are formed and decisions are made to optimize/reorganize the workplace as a whole or its individual zones.

\section{CONCLUSION}

The unfavorable economic situation, the dominance of informal norms in the regulation of economic relations and competition significantly complicate the activities of organizations of the credit and financial sector and Orient them to adaptive strategies that do not contain creative mechanisms of the working space's organization as a space in which the entire system of organizational, managerial, labor relations exists. Under these conditions, organizational stereotypes continue to be reproduced in relation to the Russian management culture as unprepared and incapable of perceiving innovative forms of management activity, which is reflected in the implementation of management practices of the 
traditional Russian management culture of the administrative and command type with the appropriate organization of the workplace as undirected to the implementation of alternative management strategies.

The need to take into account advanced technologies in the organization of workplaces of Russian credit and financial institutions' heads while maintaining a stable dependence on traditional attitudes and norms in the organization of management activities determined the development of the authors' concept to improve the organization of workplaces of institutions' heads of this profile from the standpoint of the phased implementation of three directions. The first stage is to identify the specifics and details of job descriptions and working conditions of a particular institution's head. It is advisable to use the proposed in this study passport of the workplace of the banking sector's head. In the second stage, the modeling of the head's workplace is carried out taking into account the requirements of the SOL, industry principles of activity and modern trends in the development of ergonomic knowledge, which is expressed in the proposed authors' combined model of multi-functional working space. The third stage is due to changing working conditions, changing socio-economic realities, increasing the dynamics of production life, and therefore is focused on the need for systematic assessment of specific workplaces of managers in the framework of their periodic certification in order for timely optimization and modernization. At the same time, evaluation procedures should be carried out in at least two directions: certification of the workplace from the position of SOL (including sanitary and hygienic standards) and from the position of the head (convenience of the workplace, the optimality of its organization for performing specific professional tasks, etc.). The presented step-by-step approach will allow the institutions of credit and financial type to combine traditional attitudes and modern innovations in the field of workplaces' organization of heads to optimize administrative work in the most possible mode and to avoid social and economic losses and the costs caused by inattention to this party of administrative activity's organization.

\section{ACKNOWLEDGMENT}

The author confirms that the data do not contain any conflict of interest.

\section{REFERENCES}

1. Ameen, A. M., Ahmed, M. F., \& Hafez, M. A. A. (2018). The Impact of Management Accounting and How It Can Be Implemented into the Organizational Culture. Dutch Journal of Finance and Management, $2(1), 02$. https://doi.org/10.20897/djfm/91582

2. Azhieva, I.A., and Korgova, M.A. (2018). Methods of motivation and stimulation of middle managers in the credit and financial organizations of Russia. Bulletin of Moscow University. Sociology and political science, 24(4): 225-236. https://doi.org/10.24290/1029-3736-2018-24-4-223-234

3. Bovykin, V. (2013). Improving the efficiency of Russian enterprises. We manage the company, 10(33): 146-153.

4. Courtney, S. A. (2018). Teacher Educator-Embedded Professional Learning Model. International Electronic Journal of Mathematics Education, 13(3), 103-123. https://doi.org/10.12973/iejme/2702

5. Dul, J., and Bruder, R. (2012). A strategy for human factors/ergonomics: developing the discipline and profession. Ergonomics, 55(4): 377-395. https://doi.org/10.1080/00140139.2012.661087

6. Eisvandi, M., Gorji, Y., \& Niknejadi, F. (2015). Effectiveness of Emotional Intelligence on Increasing the Psychological Dimension of Quality of Life of Mothers of Educable Mentally Retarded Children in Esfahan in. UCT Journal of Social Sciences and Humanities Research, 3(1), 29-31.

7. Gribovsky, A.V., and Lizakov, R.A. (2013). The Role of specialized financial and credit institutions in the banking system of the Russian Federation. Molodoy uchonyi, 5: 285-288.

8. Haghshenas, S., Iravani, M. R., \& Nasrabadi, H. A. B. (2015). Study Of Effective Factors On Job Satisfaction Of Omid Hospital Staff In Isfahan City. UCT Journal of Management and Accounting Studies, 3(1), 15-17.

9. Hendrick, H.W. (1991). Ergonomics in organizational design and management. Ergonomics, 34: 743-756. https://doi.org/10.1080/00140139108967348

10. Hovanec, M., Varga, M., Sobota, B., and Pačaiová, H. (2012). Inovatívne trendy a vízie v ergonómii využitím rozšírenej a virtuálnej reality. In: Aktuálne otázky bezpečnosti práce: 25 -th International conference, Štrbské Pleso. Vysoké Tatry, 2: 6 - 18.

11. Kleiner, B.M. (2008). Macroergonomics: Work System Analysis and Design. Human Factors: The Journal of the Human Factors and Ergonomics Society, 50(3): 461-467. https://doi.org/10.1518/001872008X288501

12. Korgova, M.A. and Pogosyan, S.G. (2015). Problems of choice of management principles in Russian business organizations and prospects of their resolution. Bulletin of Pyatigorsk state linguistic University, 2: 368-372.

13. Kravtsova, G.I., Kuzmenko, G.S., and Rumyantseva, O.N. (2014). Money, credit, banks. Minsk: Belarusian state University of Economic.

14. Kutuev, R.A., Katicheva, M.G., Rassolov, I.M., Derdizova, F.V., Yevgrafova, O.G., and Kozhanov, I.V. (2016). Practical recommendations on students' tolerant behavior formation in universities. International Journal of Environmental and Science Education, 11(17): 10365-10376.

15. Magomedov, M.G., Solovieva, M.N., and Arutyunyan, A.V. (2015). Social aspects of Finance as a factor in the construction of modern Russian society. Humanities, socio-economic and social Sciences, 3(11): 91-95.

16. Milgram, P., and Kishino, F.A (2014). Taxonomy of Mixed Reality Visual Displays, IEICE Transactions on Information Systems, 12: 288-297. 
17. Mintzberg, H. (1973). The Nature of Managerial Work. New York: Harper and Ron.

18. Nakhabina, J.A. (2016). improving the system of human resources management in the banking sector. Molodoy uchonyi, 11: 871-873.

19. Shim, J. P., Warkentin, M., Courtney, J. F., Power, D. J., Sharda, R., \& Carlsson, C. (2002). Past, present, and future of decision support technology. Decision support systems, 33(2), 111-126. https://doi.org/10.1016/S01679236(01)00139-7

20. Engeström, Y. (2001). Expansive learning at work: Toward an activity theoretical reconceptualization. Journal of education and work, 14(1), 133-156. https://doi.org/10.1080/13639080020028747 